\title{
Binding and the effect of the red kidney bean lectin, phytohaemagglutinin, in the gastrointestinal tract of suckling rats
}

\author{
Ann Linderoth ${ }^{1}$, Olena Prykhod'ko ${ }^{1}$, Bo Ahrén $^{2}$, Frida Fåk ${ }^{1}$, Stefan G. Pierzynowski ${ }^{1}$ and Björn \\ R. Weström ${ }^{1}$ \\ ${ }^{1}$ Department of Cell and Organism Biology, Lund University, Helgonavägen 3B, SE-223 62 Lund, Sweden \\ ${ }^{2}$ Department of Medicine, University Hospital, Lund University, Lund, Sweden
}

(Received 7 April 2005 - Revised 8 July 2005 - Accepted 17 July 2005)

\begin{abstract}
Enteral exposure of suckling rats to phytohaemagglutinin (PHA) has been shown to induce growth and precocious functional maturation of the gastrointestinal tract. The aim of the present study was to explore the mechanism of this action. Suckling rats, $14 \mathrm{~d}$ old, were fed a single dose of PHA $(0.05 \mathrm{mg} / \mathrm{g}$ body weight) or saline. The binding of PHA to the gut epithelium and its effect on the morphology and functional properties of the gut and pancreas were studied up to $3 \mathrm{~d}$ after treatment. Initially, at $1-24 \mathrm{~h}$, the PHA bound along the gut mucosal lining, resulting in disturbed gut morphology with villi shortening and rapid decreases in disaccharidase activities and macromolecular absorption capacity. During a later phase, between 1 and $3 \mathrm{~d}$, the PHA binding had declined, and an uptake by enterocytes was observed. An increase in crypt cell proliferation and gut growth became evident during this period, together with a functional maturation, as indicated by increases in disaccharidase (maltase and sucrase) activities and the low macromolecular absorption capacity. Pancreas growth also increased, as did its content of digestive enzymes. We conclude that enteral exposure to PHA in suckling rats temporarily causes mucosal disarrangement and functional impediment of the gut, which may be explained by binding to and disruption of the gut mucosa and a two-fold increase in the plasma corticosterone concentration. These findings may lead to a better understanding of the role of diet in gastrointestinal maturation and may constitute a basis for the treatment of mammals having an immature gut.
\end{abstract}

Gut permeability: Disaccharidases: Pancreas: Endocytosis

During the third postnatal week, coinciding with natural weaning, the rat gut undergoes prominent maturational changes that irreversibly adapt it for the digestion and absorption of the weaning diet. These ontogenetic changes appear to be genetically programmed, although various environmental stimuli, such as gut luminal factors and hormonal mediators, may influence its temporal progress (Lee \& Lebenthal, 1983; Henning et al. 1994; Pacha, 2000). Previous studies have shown that lectins, which are essential parts of dietary plants, may affect the gut (Pusztai et al. 1990; Bardocz et al. 1996). Thus, enteral provocation with the red kidney bean (Phaseolus vulgaris) lectin, phytohaemagglutinin (PHA), for a $3 \mathrm{~d}$ period in rats between 14 and $16 \mathrm{~d}$ of age, resulted in a more mature gut epithelium with altered disaccharidase pattern (i.e. decreased lactase and increased maltase and sucrase activities) and reduced macromolecular absorption capacity (i.e. gut closure; Linderoth et al. 2005), which in the rat normally occurs at weaning (Telemo et al. 1987). Furthermore, provocation with PHA also affected the rat pancreas, leading to an increase in its weight relative to body weight (BW) and enhanced exocrine function (Linderoth et al. 2005).

Although the effects of PHA are evident, the mechanism of action of PHA on the immature rat intestine is not known.
Studies in adult rats have shown that PHA can bind specifically to brush-border glucoconjugates of the gut epithelial cells (Cummings \& Kornfeld, 1982; Green \& Baenziger, 1987). This observation suggests that there is a direct mitogenic effect of PHA on the enterocytes, with an accelerated proliferation as a consequence (Otte et al. 2001); this correlates well with the strong trophic effects observed after enteral exposure. However, the ingestion of PHA may also have an indirect action, since the stimulation of pancreatic secretion and growth (Grant et al. 1997; Herzig et al. 1997; Pusztai, 1999) may in part be due to the release of gut peptide hormones, e.g. cholecystokinin and enteroglucagon (Herzig et al. 1997; Grant et al. 1999, 2000). In addition, PHA is reported to be transported by endocytosis through the epithelial mucosa to the general circulation, and thus may in this way contribute in a direct manner to the systemic effects (Pusztai, 1989, 1993).

The aim of the present study was to investigate further how the intestinal provocation by PHA induces functional maturation of the gastrointestinal tract in suckling rats. Alterations taken as evidence for gut maturation were foremost functional changes, such as decreased macromolecular transmission capacity, a shift in expression of the intestinal disaccharidases towards an adult pattern and an increase in pancreas enzymes. 
In addition, in the distal small gut, the replacement of the fetal type of enterocytes containing supranuclear vacuoles with adult-type enterocytes, which lack such vacuoles, was also taken as verification that the maturation process had been initiated. The binding of PHA to the gastrointestinal tract and its effect on enterocyte proliferation, small intestinal morphology, and gut and pancreas function were studied in the animals between $1 \mathrm{~h}$ and up to $3 \mathrm{~d}$ after PHA treatment. These effects were related to changes in the plasma levels of two different hormones claimed to be involved in postnatal gut maturation in the rat, corticosterone and insulin.

\section{Materials and methods}

\section{Animals}

The study was performed in rats (Rattus norvegicus) of the Sprague-Dawley stock (Mol:SPRD Han; Taconic M \& B A/S, Ry, Denmark), conventionally bred in the departmental animal unit under a controlled environment at a temperature of $20 \pm 1{ }^{\circ} \mathrm{C}$, a relative humidity of $50 \pm 10 \%$ and a $12 \mathrm{~h}$ light-12 h dark cycle. Each dam with her litter was housed individually in a polycarbonate cage (Macrolon ${ }^{\circledR}$ III; Bayer, Leverkusen, Germany) on chopped aspen wood bedding (Beekay; B \& K Universal AB, Sollentuna, Sweden), with free access to tap water and a breeding chow (Rat \& mouse autoclavable diet; B \& K Universal AB) dispensed from a lidded feed hopper. All the pups were kept with their dams and were allowed to suckle freely during the whole experimental period. The birth date of the pups was designated as day 0 , and within $2 \mathrm{~d}$ after birth the litter sizes were restricted to ten to thirteen pups each. The study was approved by the Lund University Ethical Review Committee for Animal Experiments and conducted according to European Community regulations concerning the protection of experimental animals.

\section{Preparation of phytohaemagglutinin}

Red kidney bean (P. vulgaris) lectin, PHA, was purified by affinity chromatography on Fetuin-Sepharose-4B as described previously (Herzig et al. 1997). In short, red kidney bean albumins were extracted with acetic acid from finely ground kidney beans, concentrated by ultrafiltration and dialysed against Tris- $\mathrm{HCl}$ buffer, pH 7.6 (Pusztai \& Watt, 1974). This preparation was then applied on a Fetuin-Sepharose column and washed with the Tris- $\mathrm{HCl}$ buffer, after which the bound PHA was eluted with a $0 \cdot 05-\mathrm{M}$ glycine $-\mathrm{HCl}$ buffer, $\mathrm{pH} 2 \cdot 5$, containing $0 \cdot 2-\mathrm{M} \mathrm{NaCl}$, dialysed against distilled water, and freeze-dried. The PHA preparation was pure by the criterion of producing a single protein band on PAGE.

\section{Experimental procedures}

In a set of three experiments, the pups in each litter ( $n 17$ litters) were weighed and divided into treatment $(n$ 134) and control ( $n$ 84) groups in a split-litter mode (Linderoth et al. 2005). At 07.00 hours, the 14-d-old pups were gavage-fed a single dose of PHA $(0.05 \mathrm{mg} / \mathrm{g}$ BW $)$ dissolved in saline $(0.9 \% \mathrm{NaCl})$ using a feeding tube $(0.96 \mathrm{~mm}$ outer diameter,
PE50; Becton Dickinson, Sparks, MD, USA), while the controls received the vehicle saline $(0.01 \mathrm{ml} / \mathrm{g} \mathrm{BW})$ in a corresponding manner.

In the first experiment, at 1, 3, 6, 12, 24, 48 and $72 \mathrm{~h}$ after the PHA gavage, the pups were separated from their dams and anaesthetized by light sedation in a $\mathrm{CO}_{2}$ atmosphere prior to receiving a subcutaneous injection of a mixture of azaperone (Stresnil $^{\circledR}, 30 \mu \mathrm{g} / \mathrm{g} \mathrm{BW}$; Janssen-Cilag, Vienna, Austria) and ketamin (Ketalar $^{\circledR}, 170 \mu \mathrm{g} / \mathrm{g} \mathrm{BW}$; Pfizer, Täby, Sweden) prior to sacrifice. The abdomen and thorax were then opened and blood $(0.5-1.0 \mathrm{ml})$ was collected by heart puncture into ice-chilled tubes containing $1.5 \mathrm{mg}$ EDTA and 20000 IU aprotinin (Trasylol ${ }^{\circledR}$; Bayer, Leverkusen, Germany). Plasma was obtained after centrifugation at $3000 \mathrm{~g}$ for $15 \mathrm{~min}$ at $4{ }^{\circ} \mathrm{C}$ and stored at $-70^{\circ} \mathrm{C}$ until analyses. After this the entire pancreas was removed by dissection. The small intestine, from the pylorus to the ileocaecal junction, was removed and placed on a non-absorbent surface, taking care not to stretch it, and its length was measured. The small intestine was then divided into a proximal and a distal portion of equal length and the contents were flushed out with $1 \mathrm{ml}$ ice-cold saline. The pancreas and small intestinal portions were weighed, frozen on dry ice and then stored at $-70^{\circ} \mathrm{C}$ until analysis. Finally, the stomach (after opening and rinsing with ice-cold saline to remove its contents), spleen, liver and thymus were dissected out and weighed.

In the second experiment, 14-d-old pups were divided into a PHA and a control group and thereafter treated and sacrificed as described above. For histological analyses, 1-cm-long segments were collected from the midsection of the proximal and distal portions of the small intestine, and samples were obtained from the stomach, pancreas, spleen and thymus. These samples were fixed in Bouin's solution for $24 \mathrm{~h}$, and then stored in $70 \%$ ethanol until further processing.

In the third experiment, 14-d-old pups were divided into a PHA and a control group and thereafter treated as described previously. At 1, 6, 24, 48 and $72 \mathrm{~h}$ after the PHA exposure the pups were also gavage-fed a marker molecule solution $(0.025 \mathrm{ml} / \mathrm{g} \mathrm{BW})$ containing bovine serum albumin (BSA; $1.25 \mathrm{mg} / \mathrm{g} \mathrm{BW}$ ) and bovine $\mathrm{IgG}(\mathrm{BIgG} ; 1.25 \mathrm{mg} / \mathrm{g} \mathrm{BW})$ in saline. Prior to administration, the pups had been separated from their dams for $1 \mathrm{~h}$. Three hours after the marker solution administration, the animals were anaesthetized and blood was collected as described above.

\section{Measurements}

Histology. The fixed histological samples were embedded in paraffin, cut into sections $5 \mu \mathrm{m}$ thick according to standard procedures, and stained by haematoxylin and eosin. Then, using light microscopy, the villus height and the crypt depth and width, and the small intestinal diameter (here defined as the total diameter minus the luminal diameter) were measured.

For the immunohistochemical analysis of crypt cell proliferation, the small intestinal segments were blocked for endogenous peroxidase activity, and stained using mouse monoclonal antibody against proliferating cell nuclear antigen (PCNA; DAKO A/S, Copenhagen, Denmark) as the primary antibody and goat anti-mouse horseradish peroxidase-conjugated antibodies (DAKO A/S) as the secondary antibody. To visualize the peroxidase activity, a $0.05 \%$ solution of 
3,3-diaminobenzidine tetrahydrochloride (Sigma Chemicals, St. Louis, MO, USA) was used as the substrate and the sections were counter-stained with haematoxylin, dehydrated and mounted in DPX media (BDH Chemicals Ltd, Poole, UK). The stained tissue samples were imaged using an Olympus PROVIS microscope and an Olympus DP50 camera (Olympus, Tokyo, Japan), and thereafter processed to detect the number of $\mathrm{PCNA}^{+}$cells in the crypt zone using the ImageJ software package (version 1.32; National Institutes of Health, Bethesda, MD, USA). The results were quantified by counting the numbers of $\mathrm{PCNA}^{+}$and $\mathrm{PCNA}^{-}$epithelial cells in eight to ten crypts from each portion of the small intestine (Bravo \& Macdonald-Bravo, 1987; Sheen-Chen et al. 2003).

The tissue binding of PHA was evaluated by immunohistochemical analysis using a rabbit antiserum against $P$. vulgaris agglutinin $(\mathrm{E}+\mathrm{L}$; Vector Laboratories, Burlingame, CA, USA), at dilution 1:5000, as the primary antibody and goat anti-rabbit horseradish peroxidase-conjugated antibodies (DAKO A/S) as the secondary antibody. Visualization and imaging followed the same procedures as for the immunohistochemical analysis of crypt cell proliferation. Tissue samples from the control (saline-treated) rats were used to exclude non-specific binding of the primary antibody. In addition, for all immunohistochemical analyses, IgG controls were run to check for non-specific binding of the horseradish peroxidase-conjugated secondary antibodies. To do so, the sections were incubated with $1 \%$ BSA in 0.02-M PBS instead of the primary antibody. The secondary horseradish peroxidase-conjugated antibodies were used in working dilution according to standard procedures. The staining reaction between the primary and secondary antibody was regarded as specific if the reaction with the secondary antibody alone was negative.

Intestinal and pancreatic enzymology. The proximal portion of the small intestine was thawed and homogenized in ice-cold $0.9 \% \mathrm{NaCl}(1: 10 \mathrm{w} / \mathrm{v})$ using a glass homogenizer. The disaccharidase activities (i.e. maltase, sucrase and lactase) were measured by incubating the homogenates with the appropriate disaccharide for $1 \mathrm{~h}$, after which the liberated glucose was measured using a glucose oxidase reagent (Sigma Chemicals), in accordance with the assay of Dahlqvist (1984). The protein contents of the intestinal homogenates were determined by the method of Lowry et al. (1951), modified for 96-well microplates (Pierzynowski et al. 1990), and using purified BSA (Sigma Chemicals) as the standard.

The pancreas was homogenized in ice-cold $0 \cdot 2-\mathrm{M}$ Tris $-\mathrm{HCl}$ buffer $+0.05-\mathrm{M} \mathrm{CaCl}_{2}, \mathrm{pH} 7.8(1: 10 \mathrm{w} / \mathrm{v})$ using a glass homogenizer, and centrifuged at $15000 \mathrm{~g}$ for $20 \mathrm{~min}$ at $4{ }^{\circ} \mathrm{C}$. The protein contents in the supernatants were determined according to Lowry et al. (1951). After activation with enteropeptidase (Sigma Chemicals), the trypsin activity in the supernatants was determined spectrophotometrically with a microplate modification (Pierzynowski et al. 1990) of the original method of Fritz et al. (1966), using benzoyl-DL-arginine$p$-nitroanilide (Sigma Chemicals) as the substrate. The amylase activity was analysed using Ethylidene-pNP-G7 as the substrate (Infinity $^{\mathrm{TM}}$ Amylase Liquid Stable Reagent; Thermo Electron, Victoria, Australia), according to the manufacturer's instructions.

Plasma concentrations of marker molecules. The plasma levels of the marker molecules at $3 \mathrm{~h}$ after gavage feeding were quantified by electroimmunoassay (Laurell, 1972). The BSA assay was performed using purified BSA (Sigma Chemicals) as the standard, and anti-BSA (DAKO A/S) as the precipitating antibody. The BIgG concentration was determined using purified BIgG (Sigma Chemicals) as the standard, and anti-BIgG (ICN Biomedicals, Costa Mesa, CA, USA) as the antibody.

Plasma concentrations of hormones. The plasma levels of corticosterone were quantified using a solid-phase ${ }^{125}$ I RIA (Coat-A-Count ${ }^{\circledR}$ rat corticosterone kit; Diagnostic Products Corporation, Los Angeles, CA, USA) designed for quantitatively measuring total corticosterone in rat serum, according to the manufacturer's instructions. The antiserum used was highly specific for rat corticosterone with a low risk for cross-reactivity, and concentrations as low as $5.7 \mathrm{ng} / \mathrm{ml}$ could be detected.

Plasma insulin was determined with RIA using a guinea-pig anti-rat insulin antibody, ${ }^{125}$ I-labelled human insulin as a tracer, and rat insulin as the standard (Linco Research, St Charles, MO, USA).

\section{Statistical analyses}

To compensate for individual variations in $\mathrm{BW}$, the organ measurements and the pancreas parameters are presented per g BW. All data are presented as means and standard deviations. Statistical comparisons between PHA-treated and their time-matched littermate control rats were carried out using the unpaired $t$ test (Sigma Stat software package version 2.03; SPSS Inc., Chicago, IL, USA). Differences were considered to be significant when $P<0 \cdot 05$.

\section{Results}

After exposure to a single dose of PHA by gavage feeding, the 14-d-old suckling rats were examined to determine the binding and functional effects of PHA on the gut during the period from 1 to $72 \mathrm{~h}$ after administration. In addition, the effect on the pancreas and the influence on plasma concentrations of corticosteroids and insulin were evaluated.

\section{Immunohistochemical localization of phytohaemagglutinin}

PHA could not be detected in any of the controls (results not shown), while at $1 \mathrm{~h}$ after gavage feeding, PHA was detected along the stomach and intestinal epithelium, in both the proximal and the distal intestinal regions, of the PHA-treated pups (Fig. 1(A-C)). The staining was confined to the brush-border region of the epithelial cells along the villus from its tip to the crypt-villus junction, but not in the crypt region. Later, at 3 to $6 \mathrm{~h}$ after PHA exposure, the general pattern of staining was similar, but there was an increase in the intensity and extent of the PHA staining down along the stomach glands. Between 12 and $24 \mathrm{~h}$, the staining in the stomach had subsided, but it was still visible in the small intestine (Fig. 1(D-F)). At $12 \mathrm{~h}$ after exposure, stained PHA granules could be seen in the enterocytes in the proximal portion of the intestine (Fig. 1(E)), and by $24 \mathrm{~h}$ (results not shown) in the distal portion. By $72 \mathrm{~h}$, the presence of PHA was no longer detectable in the stomach, but it could still be seen on the upper half of the small intestinal villi. In addition, PHA could be found 


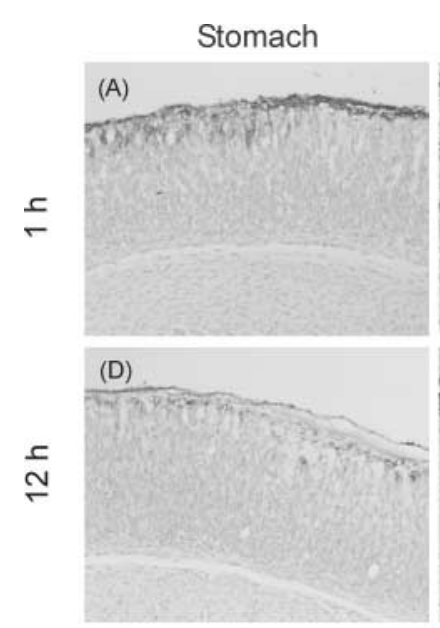

\section{Proximal SI}
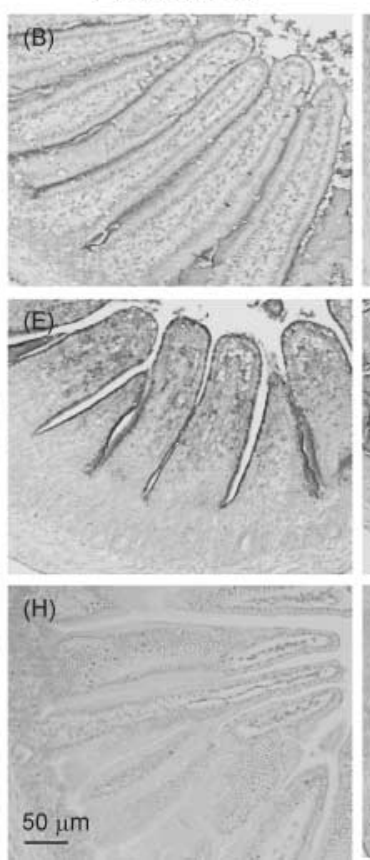

Distal SI
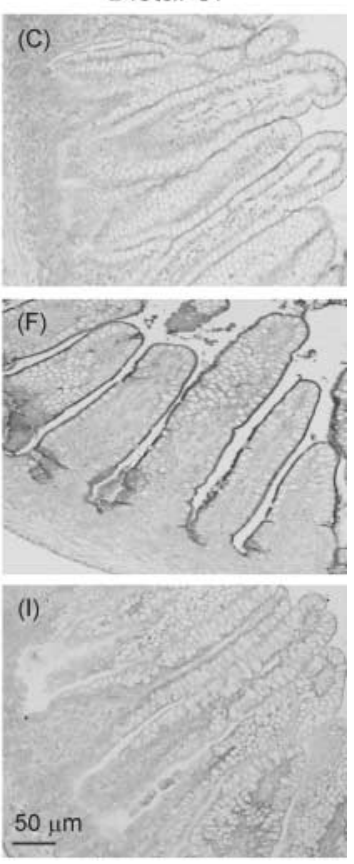

Fig. 1. Immunohistochemical localization of phytohaemagglutinin (PHA) binding in the stomach and the proximal and distal small intestine ( $\mathrm{SI}$ ), at $1 \mathrm{~h}, 12 \mathrm{~h}$ and $72 \mathrm{~h}$ after gavage feeding a single dose of PHA to 14-d-old suckling rats. PHA binding was visualized by a polyclonal anti-PHA antibody detected by Pap staining.

on the basolateral side of the enterocytes and in the lamina propria (Fig. 1(G-I)). In contrast to the observations in the gut, staining indicating the presence of PHA could not be detected in any of the extraintestinal sites, such as the pancreas, liver, kidney, thymus or spleen, at $1-72 \mathrm{~h}$ after the PHA treatment.

\section{Effect on body and organ growth}

The gavage feeding with PHA had no effect on the BW gains of the pups compared with their age-matched controls (Table 1). However, at necropsy at 3 and $6 \mathrm{~h}$ after treatment, but not at $1 \mathrm{~h}$ or at $12 \mathrm{~h}$ and thereafter, the intestine appeared to be slack and fragile, and was filled with fluid. These observations did not coincide with any statistically significant changes in the small intestinal length and weight, or with changes in the weights of the stomach, liver and pancreas. By $24 \mathrm{~h}$ after PHA treatment the distal small intestinal weight was increased in comparison to that of the control. In addition, the weights of the stomach, liver, pancreas and proximal small intestine, and the small intestinal length, were increased at $48 \mathrm{~h}$ after the PHA treatment. This effect was still evident at $72 \mathrm{~h}$ after treatment for all organs, with the exclusion of the stomach (Table 1, Fig. 2).

Table 1. The effect on body weight and weights of the stomach and liver of gavage feeding a single dose of phytohaemagglutinin (PHA) or saline (control) to 14-d-old suckling rats. Determinations were made at various times from 1 to $72 \mathrm{~h}$ after treatment

(Mean values and standard deviations for five to eight determinations)

\begin{tabular}{|c|c|c|c|c|c|c|c|c|c|c|c|c|c|c|}
\hline & \multicolumn{14}{|c|}{ Time after gavage feeding } \\
\hline & \multicolumn{2}{|c|}{$1 \mathrm{~h}$} & \multicolumn{2}{|c|}{$3 \mathrm{~h}$} & \multicolumn{2}{|c|}{$6 \mathrm{~h}$} & \multicolumn{2}{|c|}{$12 \mathrm{~h}$} & \multicolumn{2}{|c|}{$24 \mathrm{~h}$} & \multicolumn{2}{|c|}{$48 \mathrm{~h}$} & \multicolumn{2}{|c|}{$72 \mathrm{~h}$} \\
\hline \multicolumn{15}{|c|}{ Body weight (g) } \\
\hline Control & 28.9 & $2 \cdot 3$ & \multicolumn{2}{|c|}{ ND } & $28 \cdot 5$ & $2 \cdot 7$ & \multicolumn{2}{|c|}{ ND } & $30 \cdot 3$ & $3 \cdot 2$ & 31.5 & 0.8 & $33 \cdot 4$ & 0.8 \\
\hline PHA & $28 \cdot 7$ & $3 \cdot 7$ & $28 \cdot 3$ & $2 \cdot 2$ & $28 \cdot 6$ & 2.4 & $28 \cdot 1$ & 1.9 & $29 \cdot 3$ & $2 \cdot 6$ & $30 \cdot 8$ & 0.9 & $32 \cdot 1$ & 1.4 \\
\hline Control & 6.4 & 0.7 & \multicolumn{2}{|c|}{ ND } & $6 \cdot 3$ & 0.3 & \multicolumn{2}{|c|}{ ND } & $7 \cdot 1$ & 0.8 & $7 \cdot 5$ & 0.6 & $8 \cdot 2$ & 0.6 \\
\hline PHA & 6.5 & $1 \cdot 0$ & $6 \cdot 6$ & $1 \cdot 0$ & $6 \cdot 1$ & 0.9 & $6 \cdot 4$ & $1 \cdot 0$ & $7 \cdot 3$ & 0.9 & $8 \cdot 7^{\star}$ & 0.8 & $8 \cdot 8$ & 0.6 \\
\hline \multicolumn{15}{|c|}{ Weight of liver (mg/g BW) } \\
\hline Control & 30 & 5 & \multicolumn{2}{|c|}{ ND } & 28 & 4 & \multicolumn{2}{|c|}{ ND } & 35 & 6 & 33 & 1 & 40 & 1 \\
\hline PHA & 30 & 4 & 28 & 3 & 26 & 2 & 29 & 4 & 33 & 2 & $37^{* * *}$ & 1 & $42^{*}$ & 2 \\
\hline
\end{tabular}

ND, not determined.

Mean values were significantly different, PHA-treated rats $v$. their respective time-matched controls (unpaired $t$ test): ${ }^{\star} P<0.05,{ }^{* * \star} P<0.001$. 

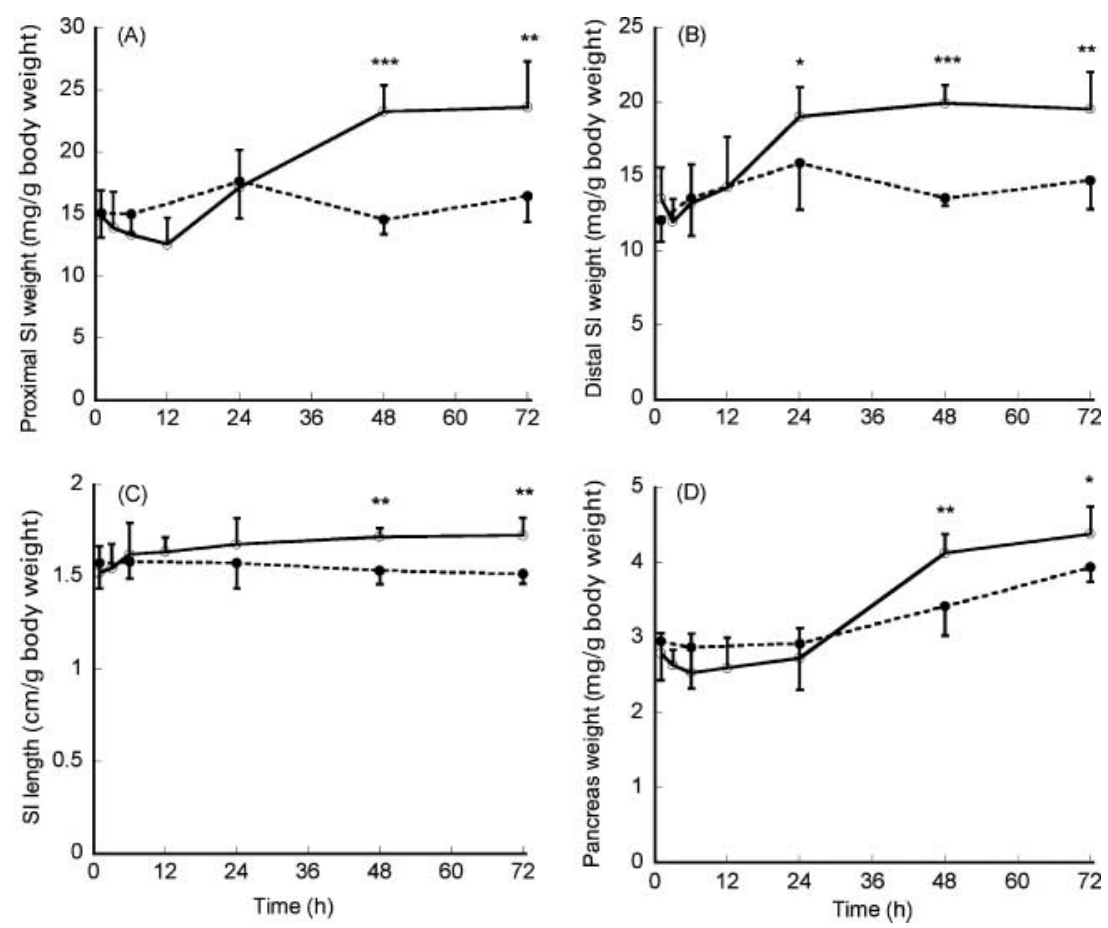

Fig. 2. The effect on intestinal and pancreas growth of gavage feeding a single dose of phytohaemagglutinin (PHA; $\bigcirc,-)$ or saline (control; $\bullet$, - - -) to 14-dold suckling rats. The weight of the proximal and distal small intestinal (SI) regions, total SI length and the weight of the pancreas were measured at various times from 1 to $72 \mathrm{~h}$ after treatment. Values are means with standard deviations shown by vertical bars $(n 4-7)$. Mean values were significantly different, PHA-treated rats $v$. their respective time-matched controls (unpaired $t$ test): ${ }^{\star} P<0.05,{ }^{\star \star} P<0.01,{ }^{\star \star \star} P<0.001$.

\section{Effects on small intestinal morphology}

During the early phase of the observation period, between 1 and $12 \mathrm{~h}$ after treatment, villus shortening was evident in the proximal small intestine, and the intestinal diameter had decreased significantly by $6 \mathrm{~h}$ after challenge (Table 2). However, PHA provocation had no effect on the crypts in the proximal small intestine during the first $12 \mathrm{~h}$, and the treatment did not induce any significant changes in the morphology of the distal region of the small intestine during this time. These early effects were followed by intestinal mucosal growth, measured as an increase in intestinal diameter and villi height, crypt size enlargement, and increase in the number of PCNA-stained crypt cells during a later phase. By 24 to $72 \mathrm{~h}$ after PHA treatment, the intestinal crypt size (depth and width) was generally enlarged throughout the small intestine. At $24 \mathrm{~h}$, these changes were accompanied by an increase in both the number of $\mathrm{PCNA}^{+}$ enterocytes and the total number of cells per crypt throughout the small intestine (Table 3). By $72 \mathrm{~h}$ after treatment, the villi length of the proximal intestinal region had increased. In the distal small intestine, the vacuolated enterocytes (immature type) were found along the whole villi in the controls (Fig. 3(A)), while in the PHA-exposed rats, a replacement of these enterocytes by cells lacking the supranuclear vacuoles (adult type) was apparent at the base of the villi at $72 \mathrm{~h}$, with the remaining vacuolated cells found to be restricted to the upper half of the villi (Fig. 3(B)).

\section{Effects on intestinal function}

The intestinal macromolecular absorption capacity, as determined by plasma concentrations of the marker molecules
BSA and BIgG, did not change in the control animals during the observation period (Table 4). However, treatment with PHA had already markedly reduced the plasma concentrations of $\mathrm{BIgG}$ and BSA at $1 \mathrm{~h}$ after treatment, and the macromolecular absorption capacity remained noticeably reduced during the entire observation period in these animals.

In addition, the activities of the brush-border disaccharidases, lactase, maltase and sucrase, in the proximal small intestinal region were affected in the PHA-fed pups. The lactase activity showed a decrease by $3 \mathrm{~h}$ after exposure, and was significantly lowered between 6 and $48 \mathrm{~h}$ after exposure, but then began to increase and was almost restored to pre-treatment levels by $72 \mathrm{~h}$ (Fig. 4(A)). The maltase and especially the sucrase activities were low in the controls rats at this time, but similar to the lactase activity, the maltase activity showed a significant decrease at $6-12 \mathrm{~h}$ due to the PHA treatment (Fig. 4(B and C)). However, both the maltase and sucrase activities began to increase noticeably after this time period, and were considerably enhanced compared with control levels by 48 and $72 \mathrm{~h}$ after treatment.

\section{Effect on the pancreas}

During the first $12 \mathrm{~h}$, PHA treatment appeared to lead to a decrease in the total pancreas protein content and the contents of the individual enzymes, trypsin and amylase, but the changes in enzyme contents were not statistically significant until after $24 \mathrm{~h}$ (Fig. 5). However, after this, the protein and trypsin contents after PHA treatment were greater than those in controls by $48 \mathrm{~h}$ and amylase by $72 \mathrm{~h}$. 
Table 2. The effect on villi length, crypt depth, crypt width and small intestinal (SI) diameter (total diameter minus the lumen diameter) of the proximal and distal small intestine of gavage feeding a single dose of phytohaemagglutinin (PHA) or saline (control) to 14-d-old suckling rats. Determinations were made at various times from 1 to $72 \mathrm{~h}$ after treatment

(Mean values and standard deviations for six to eight determinations)

\begin{tabular}{|c|c|c|c|c|c|c|c|c|c|c|c|c|c|c|}
\hline & \multicolumn{14}{|c|}{ Time after gavage feeding } \\
\hline & \multicolumn{2}{|c|}{$1 \mathrm{~h}$} & \multicolumn{2}{|c|}{$3 \mathrm{~h}$} & \multicolumn{2}{|c|}{$6 \mathrm{~h}$} & \multicolumn{2}{|c|}{$12 \mathrm{~h}$} & \multicolumn{2}{|c|}{$24 \mathrm{~h}$} & \multicolumn{2}{|c|}{$48 \mathrm{~h}$} & \multicolumn{2}{|c|}{$72 \mathrm{~h}$} \\
\hline & Mean & SD & Mean & SD & Mean & SD & Mean & SD & Mean & SD & Mean & SD & Mean & SD \\
\hline \multicolumn{15}{|c|}{ Proximal small intestine } \\
\hline \multicolumn{15}{|c|}{ Villi length $(\mu \mathrm{m})$} \\
\hline Control & 452 & 34 & \multicolumn{2}{|c|}{ ND } & 471 & 26 & \multicolumn{2}{|c|}{ ND } & 488 & 52 & 445 & 42 & 461 & 35 \\
\hline PHA & $400^{*}$ & 25 & 380 & 57 & $354^{\star \star \star}$ & 43 & 404 & 56 & $387^{\star *}$ & 52 & 472 & 17 & $531^{*}$ & 49 \\
\hline \multicolumn{15}{|c|}{ Crypt depth $(\mu \mathrm{m})$} \\
\hline Control & 45 & 5 & \multicolumn{2}{|c|}{ ND } & 54 & 7 & \multicolumn{2}{|c|}{ ND } & 52 & 4 & 48 & 5 & 60 & 5 \\
\hline PHA & 45 & 6 & 56 & 8 & 62 & 7 & 68 & 12 & $83^{\star \star \star}$ & 12 & $79^{\star \star \star}$ & 6 & 59 & 9 \\
\hline \multicolumn{15}{|c|}{ Crypt width $(\mu \mathrm{m})$} \\
\hline Control & 25 & 4 & \multicolumn{2}{|c|}{ ND } & 21 & 1 & \multicolumn{2}{|c|}{ ND } & 26 & 4 & 24 & 2 & 26 & 3 \\
\hline PHA & 23 & 2 & 22 & 4 & 24 & 3 & 25 & 3 & 29 & 3 & $32^{\star \star \star}$ & 2 & $33^{*}$ & 6 \\
\hline \multicolumn{15}{|c|}{ SI diameter $(\mu \mathrm{m})$} \\
\hline Control & 1043 & 124 & \multicolumn{2}{|c|}{ ND } & 1091 & 127 & \multicolumn{2}{|c|}{ ND } & 1135 & 126 & 1171 & 76 & 1192 & 86 \\
\hline PHA & 900 & 62 & 868 & 122 & $916^{*}$ & 138 & 1025 & 84 & 1066 & 83 & $1259^{*}$ & 78 & 1279 & 100 \\
\hline \multicolumn{15}{|c|}{ Distal small intestine } \\
\hline \multicolumn{15}{|c|}{ Villi length $(\mu \mathrm{m})$} \\
\hline Control & 455 & 56 & \multicolumn{2}{|c|}{ ND } & 499 & 44 & \multicolumn{2}{|c|}{ ND } & 524 & 45 & 570 & 51 & 594 & 50 \\
\hline PHA & 466 & 11 & 486 & 36 & 469 & 86 & 449 & 43 & 515 & 60 & 604 & 49 & 591 & 53 \\
\hline \multicolumn{15}{|c|}{ Crypt depth $(\mu \mathrm{m})$} \\
\hline Control & 49 & 6 & \multicolumn{2}{|c|}{ ND } & 50 & 5 & $\mathrm{NL}$ & & 51 & 6 & 46 & 4 & 56 & 3 \\
\hline PHA & 44 & 4 & 48 & 10 & 50 & 5 & 59 & 7 & $68^{\star \star \star}$ & 10 & $65^{\star \star \star}$ & 9 & 59 & 5 \\
\hline Crypt widtr & & & & & & & & & & & & & & \\
\hline Control & 23 & 2 & $\mathrm{~N}$ & & 27 & 4 & $\mathrm{NL}$ & & 24 & 2 & 25 & 2 & 30 & 2 \\
\hline PHA & 25 & 3 & 25 & 4 & 27 & 2 & 29 & 4 & $30^{\star}$ & 5 & $34^{\star \star *}$ & 4 & $34^{\star}$ & 4 \\
\hline SI diamete & & & & & & & & & & & & & & \\
\hline Control & 1017 & 82 & $\mathrm{~N}$ & & 1090 & 133 & $\mathrm{NL}$ & & 1141 & 87 & 1264 & 116 & 1285 & 86 \\
\hline PHA & 1081 & 59 & 1009 & 168 & 1059 & 193 & 1050 & 118 & 1184 & 90 & 1392 & 115 & $1398^{*}$ & 98 \\
\hline
\end{tabular}

ND, not determined.

Mean values were significantly different, PHA-treated rats $v$. their respective time-matched controls (unpaired $t$ test): ${ }^{\star} P<0.05,{ }^{\star *} P<0 \cdot 01,{ }^{\star * \star} P<0.001$.

Table 3. The effect on the number of cells stained positive for proliferating cell nuclear antigen (PCNA ${ }^{+}$) and total number of crypt cells from the proximal and distal small intestinal regions of gavage feeding a single dose of phytohaemagglutinin (PHA) or saline (control) to 14-d-old suckling rats. Determinations were made at various times from 1 to $72 \mathrm{~h}$ after treatment

(Mean values and standard deviations for six to eight determinations)

\begin{tabular}{|c|c|c|c|c|c|c|c|c|c|c|c|c|c|c|}
\hline & \multicolumn{14}{|c|}{ Time after gavage feeding } \\
\hline & \multicolumn{2}{|c|}{$1 \mathrm{~h}$} & \multicolumn{2}{|l|}{$3 \mathrm{~h}$} & \multicolumn{2}{|l|}{$6 \mathrm{~h}$} & \multicolumn{2}{|c|}{$12 \mathrm{~h}$} & \multicolumn{2}{|c|}{$24 \mathrm{~h}$} & \multicolumn{2}{|c|}{$48 \mathrm{~h}$} & \multicolumn{2}{|c|}{$72 \mathrm{~h}$} \\
\hline \multicolumn{15}{|c|}{$\begin{array}{l}\text { Proximal small intestine } \\
\mathrm{PCNA}^{+} \text {cells }\end{array}$} \\
\hline Control & $8 \cdot 2$ & $2 \cdot 0$ & ND & & ND & & \multicolumn{2}{|c|}{ ND } & $10 \cdot 5$ & $2 \cdot 4$ & \multicolumn{2}{|l|}{ ND } & $11 \cdot 2$ & 1.4 \\
\hline \multicolumn{15}{|c|}{ Total number of crypt cells } \\
\hline Control & $16 \cdot 3$ & 0.6 & ND & & ND & & \multicolumn{2}{|c|}{ ND } & $17 \cdot 3$ & 1.6 & \multicolumn{2}{|l|}{ ND } & $21 \cdot 2$ & $2 \cdot 2$ \\
\hline PHA & $16 \cdot 1$ & 1.7 & ND & & ND & & 20.9 & $2 \cdot 7$ & $24 \cdot 8^{\star \star \star}$ & $2 \cdot 7$ & \multicolumn{2}{|l|}{ ND } & $22 \cdot 8$ & $3 \cdot 3$ \\
\hline \multicolumn{15}{|c|}{ Distal small intestine } \\
\hline \multicolumn{15}{|c|}{$\mathrm{PCNA}^{+}$cells } \\
\hline Control & $8 \cdot 3$ & $2 \cdot 3$ & ND & & ND & & \multicolumn{2}{|c|}{ ND } & $10 \cdot 6$ & $2 \cdot 0$ & \multicolumn{2}{|l|}{ ND } & $11 \cdot 3$ & $2 \cdot 8$ \\
\hline PHA & $8 \cdot 8$ & $1 \cdot 8$ & ND & & ND & & $12 \cdot 8$ & $2 \cdot 7$ & $13 \cdot 2^{\star *}$ & $3 \cdot 1$ & \multicolumn{2}{|l|}{ ND } & 11.5 & $2 \cdot 2$ \\
\hline \multicolumn{15}{|c|}{ Total number of crypt cells } \\
\hline PHA & $16 \cdot 5$ & $2 \cdot 0$ & ND & & ND & & $20 \cdot 3$ & $2 \cdot 3$ & $22 \cdot 6^{\star \star *}$ & 2.9 & \multicolumn{2}{|l|}{ ND } & $23 \cdot 1$ & $2 \cdot 4$ \\
\hline
\end{tabular}

ND, not determined.

Mean values were significantly different, PHA-treated rats $v$. their respective time-matched controls (unpaired $t$ test): ${ }^{* \star} P<0 \cdot 01,{ }^{* \star *} P<0 \cdot 001$ 

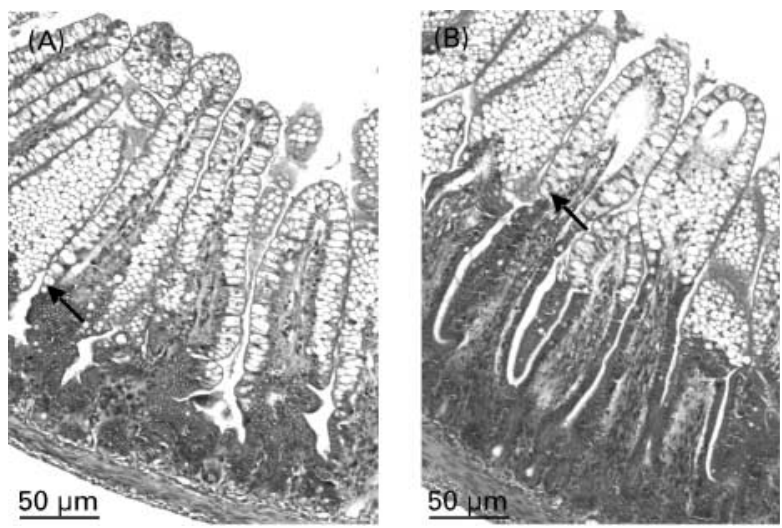

Fig. 3. Photomicrographs from the distal small intestine illustrating enterocytes containing supranuclear vacuoles $(\uparrow), 72 \mathrm{~h}$ after gavage feeding a single dose of phytohaemagglutinin (PHA) or saline (control) to 14-d-old suckling rats. The supranuclear vacuoles are restricted to the upper half of the villi in PHA-treated rats (B), as opposed to the controls $(A)$, where enterocytes containing vacuoles are found along the entire villi, from the base to the top.

\section{Effects on plasma hormone concentrations}

The total plasma corticosterone concentration was significantly elevated compared with that of the controls by $6 \mathrm{~h}$ after the PHA treatment, but not thereafter. In contrast, the plasma concentrations of insulin were unaffected by the challenge during the entire observation period (Table 5).

\section{Discussion}

The major finding of the present study was that the provocation of 14-d-old suckling rats with a single orogastric dose of PHA had profound morphologic and functional effects on the gastrointestinal tract. During the early phase, up to approximately $24 \mathrm{~h}$ after gavage feeding, the PHA bound along the gut lining, resulting in a disturbed morphology and an affected function. During the subsequent phase over the following two days, the PHA binding to the gastrointestinal mucosa declined. Moreover, it became evident that gastro- intestinal growth had been stimulated and the gastrointestinal function appeared more adult-like.

\section{Early $(1-24 h)$ effects of phytohaemagglutinin treatment}

The results confirmed that PHA binds rapidly to the gastrointestinal mucosa after exposure in the suckling rats. The PHA staining was intense and confined to the small intestinal brush-border region during the first $24 \mathrm{~h}$; after which a translocation of the PHA to the cytoplasmic granules of the enterocytes and to the lamina propria was observed. These results indicated that PHA is endocytosed and passes over the mucosal barrier, and may thereafter reach the systemic circulation. In fact, studies on adult rats have shown that $5-10 \%$ of the orogastrically administered PHA reached the blood circulation (Pusztai, 1989, 1993). On the other hand, it was not possible, using immunohistochemical methods, to detect any PHA present in the extraintestinal organs studied, the pancreas, liver, thymus or spleen, which contradicted the possibility that PHA was taken up to the blood circulation and had a direct interaction with these organs.

In addition to a tendency for a reduced weight of the small intestine, morphological changes such as a decrease in the small intestinal diameter and a shortening of the villi were evident. This indicated that there had been a decrease in the intestinal surface area in the proximal small intestine during this early phase. Also the fluid accumulation, indicative of a secretory response, and general appearance of the gut at necroscopy indicated a temporary mucosal disarrangement and a disruption of the gut due to the exposure to PHA.

In parallel to this, the intestinal function became affected. The intestinal absorption of both the receptor-mediated (FcyRn) uptake of the immunoglobulin marker BIgG, and the more unspecific marker BSA, showed a rapid decrease. In addition, the activities of the intestinal brush-border enzymes, lactase and maltase, declined markedly. This rapid effect on intestinal function could be coupled to the disruption and shortening of the intestinal enterocyte villi, probably in combination with a disarrangement and vesiculation of the microvilli (King et al. 1980; Weinman et al. 1989; Hagen et al. 1994). This would lead to a decrease in the brush-

Table 4. Plasma levels of the marker molecules, bovine $\operatorname{lgG}(\mathrm{Blg} G)$ and bovine serum albumin (BSA), $3 \mathrm{~h}$ after administration of the markers (by gavage feeding) to 14-d-old suckling rats that had been gavage-fed a single dose of phytohaemagglutinin (PHA) or saline (control). Marker molecule solutions were administered at various times from 1 to $72 \mathrm{~h}$ after treatment with $\mathrm{PHA}$ or saline

(Mean values and standard deviations for five to seven determinations)

\begin{tabular}{|c|c|c|c|c|c|c|c|c|c|c|}
\hline & \multicolumn{10}{|c|}{ Time after gavage feeding } \\
\hline & \multicolumn{2}{|c|}{$1 \mathrm{~h}$} & \multicolumn{2}{|c|}{$6 \mathrm{~h}$} & \multicolumn{2}{|c|}{$24 \mathrm{~h}$} & \multicolumn{2}{|c|}{$48 h$} & \multicolumn{2}{|c|}{$72 \mathrm{~h}$} \\
\hline & Mean & SD & Mean & SD & Mean & SD & Mean & SD & Mean & SD \\
\hline \multicolumn{11}{|c|}{$\mathrm{BSA}(\mu \mathrm{g} / \mathrm{ml})$} \\
\hline Control & 17 & 6 & \multicolumn{2}{|c|}{ ND } & 20 & 5 & 25 & 5 & 25 & 5 \\
\hline PHA & $3^{\star \star \star}$ & 1 & 3 & 1 & $1^{\star \star \star}$ & 1 & $6^{\star \star \star}$ & 4 & $9^{\star \star \star}$ & 4 \\
\hline \multicolumn{11}{|c|}{ BlgG $(\mu \mathrm{g} / \mathrm{ml})$} \\
\hline Control & 216 & 32 & \multicolumn{2}{|c|}{ ND } & 241 & 44 & 224 & 25 & 221 & 49 \\
\hline PHA & $6^{\star \star}$ & 11 & 26 & 11 & $10^{* *}$ & 21 & $12^{\star \star \star}$ & 15 & $59^{\star \star \star}$ & 36 \\
\hline
\end{tabular}

ND, not determined.

Mean values were significantly different, PHA-treated rats $v$. their respective time-matched controls (unpaired $t$ test): ${ }^{* *} P<0.01,{ }^{* * *} P<0.001$ 

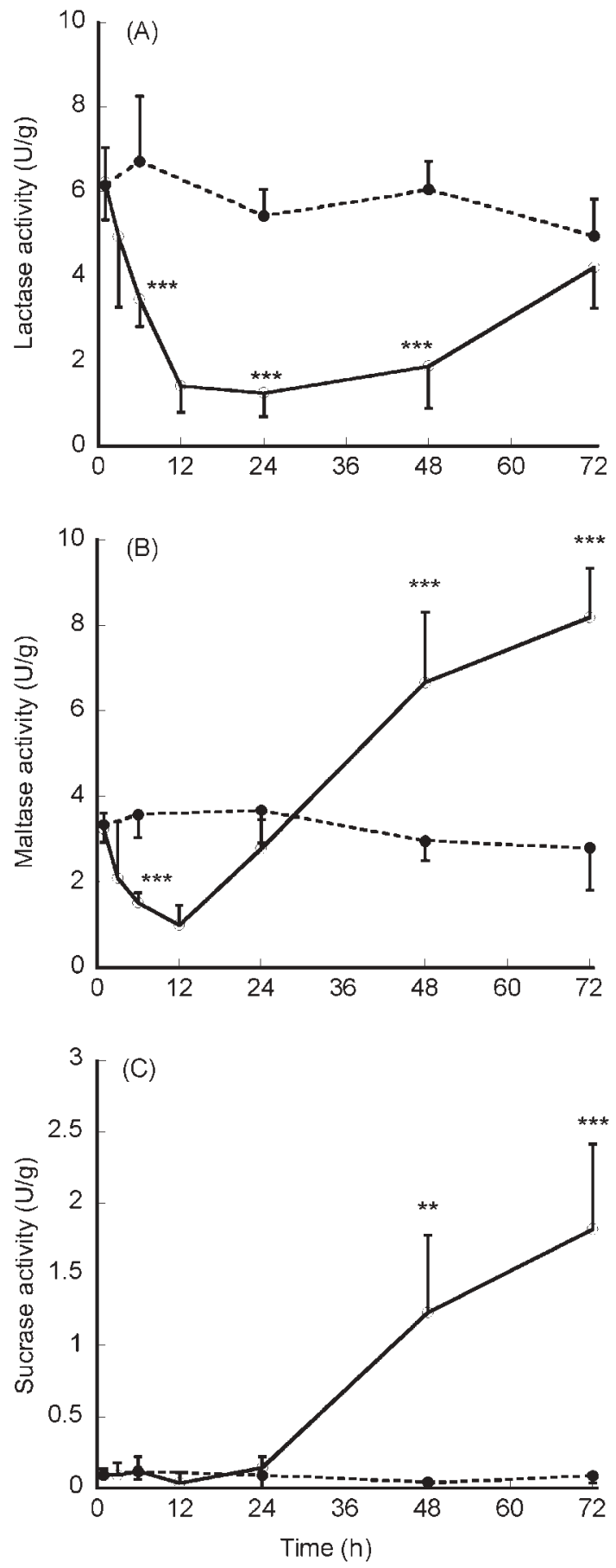

Fig. 4. The effect on activity of the mucosal disaccharidases $(\mathrm{U} / \mathrm{g}$ fresh weight), lactase (A), sucrase (B) and maltase (C), in the proximal small intestine of gavage feeding a single dose of phytohaemagglutinin ( $\mathrm{PHA} ; \mathrm{O}, \longrightarrow$ ) or saline (control; $\bullet,---$ ) to 14-d-old suckling rats. Determinations were made at various times from 1 to $72 \mathrm{~h}$ after treatment. Values are expressed as means with standard deviations shown by vertical bars $(n 5-8)$. Mean values were significantly different, PHA-treated rats $v$. their respective timematched controls (unpaired $t$ test): ${ }^{\star \star} P<0.01,{ }^{\star \star \star} P<0.001$.

border enzyme activity and would almost block the transcytotic capacity. An alternative explanation to the decreased macromolecular absorption could be that PHA, bound to the mucosa, might prevent the macromolecules from attaching to the intestinal wall, a prerequisite for adsorptive endocytosis.
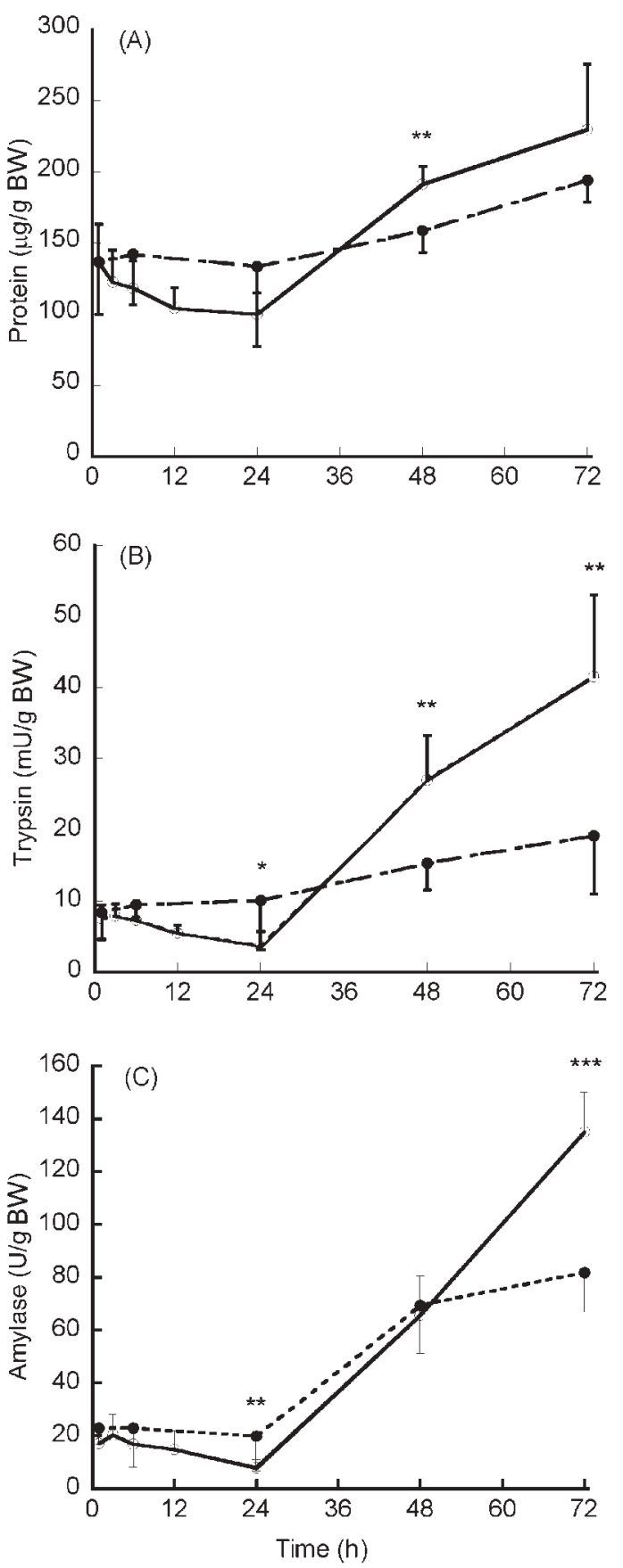

Fig. 5. The effect on total protein content (A), trypsin activity (B) and amylase activity $(\mathrm{C})$ of the pancreas of gavage feeding a single dose of phytohaemagglutinin ( $\mathrm{PHA} ; \mathrm{O},-$ ) or saline (control; $\bullet,---$ ) to 14-d-old suckling rats. Determinations were made at various times from 1 to $72 \mathrm{~h}$ after treatment (BW, body weight). Values are expressed as means with standard deviations shown by vertical bars ( $n 5-8)$. Mean values were significantly different, PHA-treated rats $v$. their respective time-matched controls (unpaired $t$ test): * $P<0.05,{ }^{\star \star} P<0.01,{ }^{\star \star \star} P<0.001$.

The present results also showed that PHA exposure affected the pancreas, an organ not in direct continuity with the PHAexposed gut in the suckling rats. Treatment led to a decrease in the enzyme contents during the early phase, indicating that pancreatic secretion had been stimulated. This observation agreed with data indicating that PHA given orally to adult 
Table 5. Plasma levels of corticosterone and insulin after gavage feeding a single dose of phytohaemagglutinin (PHA) or saline (control) to 14-d-old suckling rats. Determinations were made at various times from 1 to $72 \mathrm{~h}$ after treatment

(Mean values and standard deviations for five to eight determinations for corticosterone and five to twelve determinations for insulin)

\begin{tabular}{|c|c|c|c|c|c|c|c|c|c|c|c|c|c|c|}
\hline & \multicolumn{14}{|c|}{ Time after gavage feeding } \\
\hline & \multicolumn{2}{|c|}{$1 \mathrm{~h}$} & \multicolumn{2}{|c|}{$3 \mathrm{~h}$} & \multicolumn{2}{|c|}{$6 \mathrm{~h}$} & \multicolumn{2}{|c|}{$12 \mathrm{~h}$} & \multicolumn{2}{|c|}{$24 \mathrm{~h}$} & \multicolumn{2}{|c|}{$48 \mathrm{~h}$} & \multicolumn{2}{|c|}{$72 \mathrm{~h}$} \\
\hline & Mean & SD & Mean & SD & Mean & SD & Mean & SD & Mean & SD & Mean & SD & Mean & SD \\
\hline \multicolumn{15}{|c|}{ Corticosterone $(\mathrm{ng} / \mathrm{ml})$} \\
\hline Control & 84 & 34 & \multicolumn{2}{|c|}{ ND } & 78 & 29 & \multicolumn{2}{|c|}{ ND } & 78 & 27 & 139 & 53 & 132 & 44 \\
\hline PHA & 103 & 23 & 177 & 23 & $158^{\star \star}$ & 26 & 121 & 38 & 121 & 52 & 189 & 63 & 182 & 56 \\
\hline \multicolumn{15}{|c|}{ Insulin (pmol/l) } \\
\hline Control & 438 & 703 & \multicolumn{2}{|c|}{ ND } & 417 & 428 & \multicolumn{2}{|c|}{ ND } & 485 & 308 & 172 & 129 & 921 & 1030 \\
\hline PHA & 194 & 185 & 217 & 125 & 413 & 333 & 434 & 278 & 463 & 213 & 319 & 534 & 391 & 242 \\
\hline
\end{tabular}

ND, not determined.

Mean values were significantly different, PHA-treated rats $v$. their respective time-matched controls (unpaired $t$ test): ${ }^{* \star} P<0.01$.

rats stimulated pancreatic enzyme secretion to the duodenum, an effect that in part was mediated via a cholecystokinindependent pathway (Herzig et al. 1997; Grant et al. 1999, 2000; Pusztai, 1999). Although not specifically investigated in the present study, this effect might be explained by an indiscriminate binding of PHA to the intestinal cells, including the enteroendocrine peptide-releasing cells, resulting in a release of various pancreas-stimulating hormones.

\section{Late (24-72 h) effects of phytohaemagglutinin treatment}

During this later phase, the PHA binding had subsided or disappeared, but a strong growth-promoting effect on the gastrointestinal tract was now generally observed, as shown by the increased proliferation of small intestinal crypt cells, the enlarged villi and crypts, and heavier organ weights compared with the controls. This prominent growth-promoting effect agreed with the observations of previous studies on suckling rats that had received PHA for a $3 \mathrm{~d}$ period, as well as those of other studies on PHA-treated adult rats (Pusztai et al. 1990; Banwell et al. 1993; Herzig et al. 1997; Linderoth et al. 2005).

Already by $24 \mathrm{~h}$ after PHA gavage feeding, gut function appeared to be partially restored, and over the following two days showed an alteration in function in comparison to that shown by the controls. This was accompanied by a change from a neonatal phenotype of disaccharidase expression to resemble that of an adult phenotype, with a striking increase in the maltase and sucrase activities. In addition, the macromolecular absorptive capacity was considerably reduced, which also agreed with the presence of an adult-like phenotype, i.e. with intestinal closure that normally occurs at weaning, at 3 weeks of age.

In addition it was noted that, by $48-72 \mathrm{~h}$ after challenge, the PHA treatment had stimulated pancreas growth and maturation, as the total pancreas protein content and the pancreatic enzyme contents had increased. It was likely that PHA exposure affected pancreas growth and function in part as a result of the release of gut-stimulating hormones, e.g. cholecystokinin (Herzig et al. 1997; Grant et al. 1999; Pusztai, 1999). Moreover, glucocorticoids, thyroxine and insulin have been suggested to be involved in pancreatic development in the rat (Henning, 1987; Puccio et al. 1988; Kinouchi et al.
1998). Accordingly, since the corticosterone concentration was increased, this hormone might have contributed to the stimulatory effect on the pancreas after the PHA treatment.

\section{Possible mediators/pathways of regulation}

The results showed that PHA treatment led to an increase in plasma corticosterone concentration during the early phase (1-24h), implying that this hormone was involved in the induction of the maturation-like effects on the gastrointestinal tract. Glucocorticoids have previously been shown to be involved in gastrointestinal maturation in rats (Puccio et al. 1988; Martin et al. 1993; Henning et al. 1994; Polk \& Barnard, 2000; Biol-N'garagba et al. 2003). In fact, during normal postnatal development, the concentration of circulating glucocorticoids has been observed to increase approximately 2 $d$ prior to the initiation of the functional changes that occur around weaning, such as the changes in pancreatic and intestinal digestive enzyme activities and the cessation of intestinal macromolecular absorption (Henning et al. 1994; Polk \& Barnard, 2000). Exogenous administered glucocorticoids are also known to be capable of eliciting the precocious expression of sucrase activity and the disappearance of the neonatal Fc $\gamma \mathrm{Rn}$ (Yeh et al. 1989; Martin et al. 1993; Henning et al. 1994; Pacha, 2000). Then again, several studies have supported the presence of a glucocorticoid-independent pathway in gastrointestinal maturation (Henning et al. 1994; Pacha, 2000), and some studies have demonstrated that endogenous adrenal steroids were not entirely responsible for the age-dependent decline of $\operatorname{IgG}$ transport (Martin et al. 1993). In addition, neither adrenalectomy nor the administration of glucocorticoid antagonists could totally abolish intestinal maturation (Henning et al. 1994; Nanthakumar \& Henning, 1995; Pacha, 2000).

Insulin and insulin-like growth factor have also been suggested to be involved in gastrointestinal maturation (Young et al. 1990; Kinouchi et al. 1998, 2000; Polk \& Barnard, 2000). PHA has been shown to have an insulin-mimicking effect in vitro and, in fact, after long-term exposure to PHA in the adult rat, insulin plasma concentrations showed a decrease (Pusztai \& Watt, 1974; Pusztai et al. 1995; Bardocz et al. 1996). In the light of this, it would be possible that PHA could elicit some of its effects on gut maturation by mimick- 
ing these hormones. However, the present data indicated that PHA exposure did affect plasma concentrations of insulin, suggesting that insulin was not involved in the PHA-induced maturation of the suckling rat.

In conclusion, in suckling rats exposure to PHA initially disrupts the gut, with mucosal disarrangement and functional impediment as a consequence. This initial effect is, however, temporary, and during a later phase a stimulatory response of the gut to the PHA can be observed, characterized by increased growth and induced maturation of the gastrointestinal tract and pancreas function. This is manifested by an alteration in the enterocyte phenotype, from a neonatal to a more adult one, with changed disaccharidase pattern, a decrease in macromolecular absorptive capacity, and displacement of the supranuclear vacuole-containing enterocytes. Binding of PHA to the intestinal villi, with a subsequent acceleration of cell turnover and increase in plasma corticosterone concentrations, appears to be involved in the mechanism of these actions. These findings may lead to a better understanding of the role of diet in gastrointestinal maturation and may constitute a basis for the treatment of mammals having an immature gut.

\section{Acknowledgements}

We would like to thank Inger Mattsson and Lilian Bengtsson for their help with the analyses. The Swedish Research Council for Environment, Agricultural Sciences and Spatial Planning (FORMAS), the Swedish Agency for Innovation Systems, the Swedish Research Council (grant no. 6834) and The Royal Physiographic Society of Lund are also gratefully acknowledged for their financial support.

\section{References}

Banwell JG, Howard R, Kabir I, Adrian TE, Diamond RH \& Abramowsky C (1993) Small intestinal growth caused by feeding red kidney bean phytohemagglutinin lectin to rats. Gastroenterology 104, 1669-1677.

Bardocz S, Grant G \& Pusztai A (1996) The effect of phytohaemagglutinin at different dietary concentrations on the growth, body composition and plasma insulin of the rat. Br J Nutr 76, 613-626.

Biol-N'garagba MC, Niepceron E, Mathian B \& Louisot P (2003) Glucocorticoid-induced maturation of glycoprotein galactosylation and fucosylation processes in the rat small intestine. J Steroid Biochem Mol Biol 84, 411-422.

Bravo R \& Macdonald-Bravo H (1987) Existence of two populations of cyclin/proliferating cell nuclear antigen during the cell cycle: association with DNA replication sites. J Cell Biol 105, $1549-1554$.

Cummings RD \& Kornfeld S (1982) Characterization of the structural determinants required for the high affinity interaction of asparagine-linked oligosaccharides with immobilized Phaseolus vulgaris leukoagglutinating and erythroagglutinating lectins. J Biol Chem 257, 11230-11234.

Dahlqvist A (1984) Assay of intestinal disaccharidases. Scand J Clin Lab Invest 44, 169-172.

Fritz H, Hartwich G \& Werle E (1966) On protease inhibitors. I. Isolation and characterization of trypsin inhibitors from dog pancreas tissue and pancreas secretion. Hoppe Seylers Z Physiol Chem 345, 150-167.
Grant G, Alonso R, Edwards JE \& Murray S (2000) Dietary soya beans and kidney beans stimulate secretion of cholecystokinin and pancreatic digestive enzymes in 400-day-old Hooded-Lister rats but only soya beans induce growth of the pancreas. Pancreas 20, 305-312.

Grant G, Edwards JE, Ewan EC, Murray S, Atkinson T, Farningham DA \& Pusztai A (1999) Secretion of pancreatic digestive enzymes induced in rats by first-time oral exposure to kidney bean E2L2 lectin is mediated only in part by cholecystokinin (CCK). Pancreas 19, 382-389.

Grant G, Henderson LT, Edwards JE, Ewan EC, Bardocz S \& Pusztai A (1997) Kidney bean and soybean lectins cause enzyme secretion by pancreatic acini in vitro. Life Sci 60, 1589-1595.

Green ED \& Baenziger JU (1987) Oligosaccharide specificities of Phaseolus vulgaris leukoagglutinating and erythroagglutinating phytohemagglutinins. Interactions with $N$-glycanase-released oligosaccharides. J Biol Chem 262, 12018-12029.

Hagen SJ, Trier JS \& Dambrauskas R (1994) Exposure of the rat small intestine to raw kidney beans results in reorganization of absorptive cell microvilli. Gastroenterology 106, 73-84.

Henning SJ (1987) Functional development of the gastrointestinal tract. In Physiology of the Gastrointestinal Tract, 2nd ed., pp. 285-300 [LR Johnson, editor]. New York: Raven Press.

Henning SJ, Rubin DC \& Shulman RJ (1994) Ontogeny of the intestinal mucosa. In Physiology of the Gastrointestinal Tract, 3rd ed., pp. 571-610 [LR Johnson, editor]. New York: Raven Press.

Herzig KH, Bardocz S, Grant G, Nustede R, Folsch UR \& Pusztai A (1997) Red kidney bean lectin is a potent cholecystokinin releasing stimulus in the rat inducing pancreatic growth. Gut 41, 333-338.

King TP, Pusztai A \& Clarke EMW (1980) Immunocystochemical localization of ingested kidney bean (Phaseolus vulgaris) lectins in rat gut. Histochem J 12, 201-208.

Kinouchi T, Koizumi K, Kuwata T \& Yajima T (1998) Crucial role of milk-borne insulin in the development of pancreatic amylase at the onset of weaning in rats. Am J Physiol 275, R1958-R1967.

Kinouchi T, Koizumi K, Kuwata T \& Yajima T (2000) Milk-borne insulin with trypsin inhibitor in milk induces pancreatic amylase development at the onset of weaning in rats. J Pediatr Gastroenterol Nutr 30, 515-521.

Laurell CB (1972) Electroimmunoassay. Scand J Clin Lab Invest Suppl 124, 21-37.

Lee PC \& Lebenthal E (1983) Early weanling and precocious development of small intestine in rats: genetic, dietary or hormonal control. Pediatr Res 17, 645-650.

Linderoth A, Biernat M, Prykhodko O, Kornilovska I, Pusztai A, Pierzynowski SG \& Weström B (2005) Induced growth and maturation of the gastrointestinal tract after Phaseolus vulgaris lectin exposure in suckling rats. J Pediatr Gastroenterol Nutr 41, 195-203.

Lowry OH, Rosebrough NJ, Farr AL \& Randall RJ (1951) Protein measurements with folin phenol reagent. J Biol Chem 193, 265-275.

Martin MG, Wu SV \& Walsh JH (1993) Hormonal control of intestinal $\mathrm{Fc}$ receptor gene expression and immunoglobulin transport in suckling rats. $J$ Clin Invest 91, 2844-2849.

Nanthakumar NN \& Henning SJ (1995) Distinguishing normal and glucocorticoid-induced maturation of intestine using bromodeoxyuridine. Am J Physiol 268, G139-G145.

Otte JM, Chen C, Brunke G, Kiehne K, Schmitz F, Folsch UR \& Herzig KH (2001) Mechanisms of lectin (phytohemagglutinin)induced growth in small intestinal epithelial cells. Digestion 64, $169-178$.

Pacha J (2000) Development of intestinal transport function in mammals. Physiol Rev 80, 1633-1667.

Pierzynowski SG, Weström BR, Svendsen J \& Karlsson BW (1990) Development of exocrine pancreas function in chronically cannulated pigs during 1-13 weeks of postnatal life. J Pediatr Gastroenterol Nutr 10, 206-212. 
Polk BD \& Barnard JA (2000) Hormones and growth factors in intestinal development. In Development of the Gastrointestinal Tract, pp. 37-56 [IA Sanderson and WA Walker, editors]. Hanilton, Ontano, Canada: B.C. Decker Inc.

Puccio F, Chariot J \& Lehy T (1988) Influence of hydrocortisone on the development of pancreas in suckling rats. Ultrastructural morphometric and biochemical studies. Biol Neonate 54, 35-44.

Pusztai A (1989) Transport of proteins through the membranes of the adult gastrointestinal tract - a potential for drug delivery?" $A d v$ Drug Deliv Rev 3, 215-228.

Pusztai A (1993) Dietary lectins are metabolic signals for the gut and modulate immune and hormone functions. Eur J Clin Nutr 47, 691-699.

Pusztai A (1999) Phytohaemagglutinin stimulates pancreatic enzyme secretion in rats by a combination of cholecystokinin- and noncholecystokinin-linked pathways. In Biology of the Pancreas in Growing Animals, pp. 273-286 [SG Pierzynowski and R Zabielski, editors]. Amsterdam: Elsevier Science BV.

Pusztai A \& Watt WB (1974) Isolectins of Phaseolus vulgaris. A comprehensive study of fractionation. Biochim Biophys Acta 365, 57-71.

Pusztai A, Ewen SW, Grant G, Peumans WJ, van Damme EJ, Rubio L \& Bardocz S (1990) Relationship between survival and binding of plant lectins during small intestinal passage and their effectiveness as growth factors. Digestion 46, 308-316.

Pusztai A, Ewen SWB, Carvalho FFU, G.G, Baintner K \&, Bardocz S (1995) Dietary lectins affect the hormone balance of the body and modulate its general metoblosim. In Gastrointestinal Tract and Endocrine system, pp. 457-463 [MV Singer, Z Riegler and G Rohr, editors] Dordrecht, The Netterlands: Kluwer Acodemic Publishers.

Sheen-Chen SM, Ho HT, Chen WJ \& Eng HL (2003) Obstructive jaundice alters proliferating cell nuclear antigen expression in rat small intestine. World J Surg 27, 1161-1164.

Telemo E, Westrom BR, Ekstrom G \& Karlsson BW (1987) Intestinal macromolecular transmission in the young rat: influence of protease inhibitors during development. Biol Neonate 52, 141-148.

Weinman MD, Allan CH, Trier JS \& Hagen SJ (1989) Repair of microvilli in the rat small intestine after damage with lectins contained in the red kidney bean. Gastroenterology 97, 1193-1204.

Yeh KY, Yeh M \& Holt PR (1989) Differential effects of thyroxine and cortisone on jejunal sucrase expression in suckling rats. Am J Physiol 256, G604-G612.

Young GP, Taranto TM, Jonas HA, Cox AJ, Hogg A \& Werther GA (1990) Insulin-like growth factors and the developing and mature rat small intestine: receptors and biological actions. Digestion 46, $240-252$. 